\title{
Ueber die Behandlung und Konservirung von rohem Fleisch.
}

\author{
Von
}

R. Emmerich in München.

Vorgetragen von C. Mai anf der 19. Jahresversammlung der freien Vereinigung bayerischer Vertreter der angewandten Chemie zu Bamberg.

Mit Recht hat Professor Franz Hofmann auf der Versammlung des Vereins für öffentliche Gesundheitspflege zu Leipzig 1892 gesagt, dass man im allgemeinen das Fleisch wie Ptlastersteine behandele wnd herumwerfe.

Man kann sich täglich in jedem Schlachthaus überzengen, dass die Schlachtung im allgemeinen in sehr unreinlicher Weise vollzogen wird und dass ganz unnöthiger Weise Oberflächen- und Tiefeninfektionen verursacht werden, welche die Haltbarkeit des Fleisches in hohem Maasse beeinträchtigen, aber sehr leicht zu vermeiden wären.

Der Metzger sticht z. B. das Messer, mit dem er das Fell durchschnitten und das er oft an dem so keimreichen Fell abgestrichen hat, tief in das Fleisch hinein, anstatt es bei Seite zu legen, oder in die Scheide zu stecken. Dadurch werden Heubacillen und andere sporenbildende Bakterien in die Stichwunde geführt und gefährliche Tiefeninfelitionen veranlasst. Sehr oft wird der Darm angeschnitten, so dass durch den in die Bauchhöhle austretenden Koth ebenfalls eine Masseninfektion verursacht wird. Das Gleiche geschieht beim Auswaschen des Blutes aus Brust- und Bauchböhle, wozu meistens alte, mit fanlendem Blut imprägnirte Tücher 100- und 1000-mal benutzt werden. Während reines Quellund Brunnenwasser sonst das vorzüglichste und unentbehrliche Reinigungsmittel ist, muss dessen Verwendung zum Reinigen der Brust- und Bauchhöhle und von Fleisch überhaupt, als höchst unzweckmässig bezeichnet werden, weil fast in jedem Quell- und Brunnenwasser Keime des Bac. fluorescens liquefaciens enthalten sind, welcher einer der gefäbrlichsten Fleischrerderber ist, da $\in \mathrm{r}$, namentlich im Sommer das Fleisch in kurzer Zeit grün färbt und stinkende, sich rasch ausbreitende Fäulniss verursacht. Fleisch sollte daher ängstlich vor der Beriihrung mit Wasser geschïtzt werden.

Die erste Bedingung erfolgreicher Konservirnng von Rohfleisch oder von Fleischwaaren, ist reinliche, am besten aseptische Schlachtung. Die Konservirung von Rohfleisch kann ferner nur dann gelingen; wenn durch das betreffende Verfahren die Bethaung der Fleischoberfläche mit aus der Luft sich kondensirendem Wasser sicher verhïtet wird, da diese Bethanung in Folge der verschiedenen Temperatur der Fleischtheile und der Luft sehr bäufig erfolgt und weil das kondensirte Wasser isolirte, sonst ungefährliche Bakterien- oder Pilz-Kolonien über die Oberfläche der Fleischstïcke hinweg schwemmt, so dass eine Massenaussaat von Keimen auf einem grösseren oder geringeren Theil der Fleischoberfläche zu Stande kommt.

Die Verwendung von Konservirungsmitteln, welche behufs Erhaltung rohen Fleisches auf die Oberfläche der Fleischstücke gebracht werden, ist bei der N. 01 . 
gewöhnlichen Ausführung der Schlachtung werthlos. Fleisch kann hierdurch nicht konservirt werden, weil die in den zahlreichen Falten, Nischen und Höhlungen der Fleischtheile haftenden Keime und namentlich die durch Messerstiche etc, in die tieferen Schichten gelangten Bakterien und Schimmelpilze durch das Aufstreuen von Konservirungsmitteln, wie Borsäure etc., oder durch das Einstäuben von desinficirenden Flüssigkeiten nicht getroffen und geschädigt werden. Solches Fleisch unterliegt trotz überreicher Anwendung ron Borsäure, Ameisensäure oder anderen Konservirungsmitteln, in kurzer Zeit dem Verderben.

Als ein Beispiel eines erfolgreichen, hauptsächlich auf reinliche Schlachtung sich gründenden Verfahrens der Fleischkonservirung beschreibt Emmerich die von Dr. Deichstätter und ihm ausgearbeitete Methode und macht dabei auf die Forderungen aufmerksam; welche bei der Aufbewahrung und Konservirung von Fleisch und Fleischwaaren überhaupt im Interesse der Gesundheit der Konsumenten erfüllt werden müssen. Das Verfahren besteht ausser der aseptischen Schlachtung im Besprühen der Schnittflächen bezw. Fleischoberflächen mit Eis= essig und Einpacken der geschlachteten ganzen Thiere oder der Fleischstücke in sterilisirte Sägespähne.

Prof. Emmerich verzichtet darauf bestimmte Resolutionen in Vorschlag $\mathrm{zu}$ bringen, glaubt aber, dass die freie Vereinigung bayerischer Vertreter der angewandten Chemie der Sache auch in Zukunft ihr Interesse zuwenden und späterhin bestimmte Regeln für die Ausführung der Schlachtung und die Behandlung von Fleisch und Fleischwaaren vereinbaren sollte, welche alsdann in den ortspolizeilichen Vorschriften, betreffend den Verkehr mit Nahrungsund Genussmitteln, sowie in den Schlachtvorschriften der Städte Aufnahme finden dürften.

\title{
Wann ist eine Fleischwaare als rerdorben zu betrachten?
}

\section{Von}

\author{
Dr. C. Mai in München.
}

Vortrag, gehalten auf der 19. Jahresversammlung der freien Vereinigung bayerischer Vertreter der angewandten Chemie zu Bamberg.

Wohl kaum eines der wichtigeren Nahrungsmittel ist - namentlich in den heisseren Jahreszeiten und bei mangelhafter Aufbewahrung - so leicht dem "Verderben" ausgesetzt, als das Fleisch und die verschiedenen Arten der Fleischwaaren. Häufig tritt daher an den Nahrungsmittelchemiker die Aufgabe heran, das "Verdorbensein" einer Fleischwaare auf Grund chemischer Untersuchung und unter Angabe zuverlässiger Thatsachen mit Sicherheit festzustellen.

Fs darf wohl ausgesprochen werden, dass seine Lage in diesem Falle keine ganz leichte und besonders angenehme ist. Denn die Methoden, die ihm hierbei zur Verfügung stehen sind bekanntermassen mehr als dürftig. So erklären 